\title{
Spiritual Care Intervention on Emotional Regulation in Caregivers with Schizophrenic : A Systematic Review
}

\author{
Maulidiyah Junnatul Azizah Heru' ${ }^{1}$, Rizki Fitryasari ${ }^{*}$, Hendy Muagiri Margono² \\ ${ }^{I}$ Faculty Of Nursing, Airlangga University, Indonesia \\ ${ }^{2}$ Faculty Of Medicine, Airlangga University, Indonesia \\ *rizki-fpk@fkp.unair.ac.id
}

\begin{abstract}
Schizophrenic client caregivers are faced with various problems caused by the abnormal behavior of schizophrenic clients that can trigger stress. The stress experienced by the schizophrenia client caregiver is indicated by the decrease in emotional control which has an impact on the treatment of schizophrenic clients. This research aimed to determine the effectiveness of spiritual care in improving the emotional regulation of caregiver clients with schizophrenia. The sources of the articles used were obtained from searches through the Scopus database Google Scholar, Science Direct, and Proquest. The search for articles is limited from 2015 to 2020 . After the articles are obtained, they are then reviewed until the stage of making a systematic review. The keywords used in the article search were "spiritual care", "Emotional Regulation" "Caregiver". This systematic review uses 15 articles that fit the inclusion criteria. The spiritual care intervention from the reviewed research is very significant in increasing the emotional regulation of the caregiver in schizophrenic clients. Spiritual care strategy can increase emotional regulation and calm attitude so that it will have a good impact on the recovery process for schizophrenic clients. We recommend spiritual care strategies to be implemented by health workers in the community as an intervention to improve the caregiver's ability to improve emotional regulation.
\end{abstract}

Keywords : Spiritual Care, Emotion Regulation, Caregiver 


\section{STRADA Jurnal Ilmiah Kesehatan}

DOI: $10.30994 /$ sjik.v9i2.386

ISSN: 2252-3847 (print); 2614-350X (online)

Vol.9 No.2 November 2020 Page.790-800

\section{BACKGROUND}

A severe mental illness such as schizophrenia not only affects the sufferer but also the caregiver (Von Kardorff, Soltaninejad, Kamali, \& Shahrbabaki, 2016). Caring for schizophrenia in the long term creates a burden for caregivers who care for schizophrenia clients at home (Marlindawani Purba \& Karota Bukit, 2017).

According to WHO data (2016), there are about 35 million people affected by depression, 60 million people with bipolar disorder, 21 million affected by schizophrenia, and 47.5 million affected by dementia. Based on Riskesdas 2018 data, the prevalence of the Indonesian population with severe mental disorders schizophrenia/psychosis is 7.0 per mil, this data has increased where the prevalence of Riskesdas 2013 data is 1.7 peril. While in East Java the prevalence was 5.2 peril, increased from Riskesdas in 2013 which was 2.2 peril.

Among mental illness, schizophrenic patients have the highest level of burden on their caregivers (Altamura, Fagiolini, Galderisi, Rocca, \& Rossi, 2014). Stress causes emotional dysregulation, which in turn will cause disturbances to their psychological and physiological health (Compare, Zarbo, Shonin, Van Gordon, \& Marconi, 2014)). Spirituality can be a strong source of support for individuals and can have a huge effect on their health, including their mental health (Nikseresht et al., 2016)

\section{METHODS}

Database searches include Scopus, Google Scholar, Science Direct, and Proquest with the keywords spiritual care, emotional regulation, schizophrenic client caregiver. The next step is to select articles according to the criteria, namely published in 2015-2020 with full text and in English, in the preparation of this systematic review based on Preferred Reporting Items for Systematic Reviews and Meta-Analyses (PRISMA). The articles that were found were then synthesized and analyzed according to the inclusion and exclusion criteria. The inclusion criteria in this systematic review are (1) caregivers who have family members with schizophrenia. (2) The study that examines spiritual care intervention in caregivers who cares for schizophrenic clients, (3) the same study design is quasi-experimental, experimental and randomized controlled trial (RCT), while the exclusion criteria in this systematic review are (1) articles that use qualitative research methods, (2) studies that focus on treating schizophrenic clients without involving caregiver interventions. Search for articles starts from June 2020 to July 2020, with keywords that have been determined by the researcher. The articles found by the researcher were selected according to inclusion and exclusion criteria, with the keywords spiritual care, emotional regulation, schizophrenic client caregiver. The researcher removes the same articles, examines articles that meet the criteria, and classifies them according to the results of the research to be continued with the discussion.

\section{RESULT}

The initial literature search found 95 articles. Researchers select articles with the same title, then the remaining 85 articles. The screening based on the title was then adjusted to the theme of a systematic review, which resulted in 50 articles. Selection based on abstract were excluded and obtained 40 articles. From 40 articles then selected according to the eligibility criteria and obtained 15 articles which were subsequently used in a systematic review as shown in Figure 1. 


\section{STRADA Jurnal Ilmiah Kesehatan}

DOI: $10.30994 /$ sjik.v9i2.386

ISSN: 2252-3847 (print); 2614-350X (online)

Vol.9 No.2 November 2020 Page.790-800

Figure 1. Flow diagram and article selection

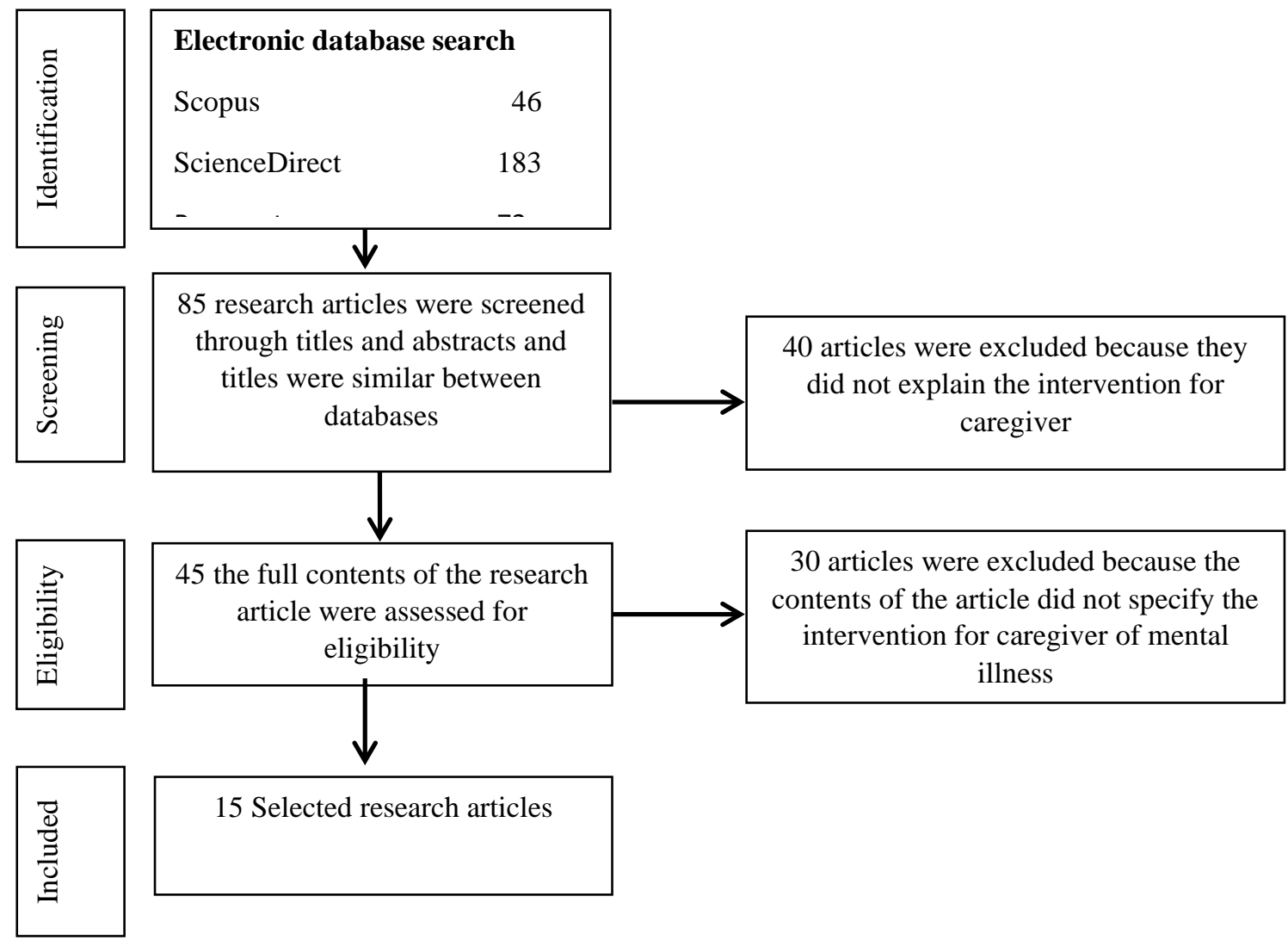

Research articles are limited from 2015 to 2020. Three articles are published in 2016, three articles are published in 2017, five articles are published in 2019, and four articles are published in 2020. All research articles are quantitative research with a quasiexperimental, experimental, and randomized controlled trial research design. All studies have shown significant results in reducing stress and improving psychological well-being. Spiritual care therapy can improvement in symptoms of anxiety and depression (Sankhe, Dalal, Save, \& Sarve, 2017). Spiritual care can enhance the self-efficacy of the family caregivers of people who suffer from Alzheimer's disease, Spiritual care can enhance the self-efficacy of the family caregivers of people who suffer from Alzheimer's disease (Salamizadeh, Mirzaei, \& Ravari, 2017), The hope, life satisfaction, and spiritual wellbeing of elderly patients with mild or moderate dementia could significantly be improved(Wu \& Koo, 2016), and the spirituality therapy using techniques such as knowing values and a deep belief in God can decrease social stigma and worry (Mousavi Najafi \& Rasouli Jozi, 2019). Research sites were carried out in various countries, namely India, Taiwan, Iran, Spain, and California.

This systematic review research study identifies the spiritual care can reduce stress and improving psychological well-being with improving emotion regulation. Ten of the fifteen studies have shown that spiritual care can reduce stress and improving psychological wellbeing. Among mental illness, schizophrenic patients have the highest level of burden on their caregivers. Stress causes emotional dysregulation, which in turn affects their psychological and physiological health. Therefore, preventive interventions to reduce stress, anxiety, anger, and depression are very important in reducing the occurrence of other disorders in the caregiver's life, and emotional regulation is one of the factors that 


\section{STRADA Jurnal Ilmiah Kesehatan}

DOI: $10.30994 /$ sjik.v9i2.386

ISSN: 2252-3847 (print); 2614-350X (online)

Vol.9 No.2 November 2020 Page.790-800

have the potential to reduce the incidence of negative emotions in the caregiver. The results of this study can be seen in Table 1 .

Table 1. Characteristics of research articles

Research Title Research methods
Evaluation of the effect of Design: RCT
Spiritual care on patients Sample: 110 participants
with generalized anxiety and Variables: Spiritual care,
depression: a randomized patients with generalized
controlled study (Sankhe et anxiety and depression
al., 2017)
Intervention: Spiritual care
Analyze: Descriptive
statistics ,Friedman test

The Impact of Spiritual Care Design: RCT

Education on the Self- Sample: 60 family caregivers Efficacyr of the Family Variables: Spiritual Care Caregivers of Elderly Education,

People with Alzheimer's Intervention: Spiritual Care Disease (Salamizadeh et al., Education, Family Caregivers 2017) of Elderly People with Alzheimer's Disease

Analyze: Chi-square and independent t-test.

Randomized controlled trial Design: RCT

of a six-week spiritual Sample: 103 patients

reminiscence intervention on Variables:

spiritual

hope, life satisfaction, and reminiscence intervention,

spiritual well-being in Intervention: hope, life

elderly with mild and satisfaction, and spiritual moderate dementia ( $W u$ \& well-being

Koo, 2016) Analyze: Chi-squared test

Effectiveness of Spirituality Design: quasi-experimental The spirituality therapy using

Therapy on Social Stigma study

and Worry in the Mothers of Sample: 40 mothers were

the Children with Autism Variables: Spirituality

(Mousavi Najafi \& Rasouli Therapy, Social Stigma and Jozi, 2019)

Worry in the Mothers

This suggests a significant improvement in symptoms of anxiety and depression in the spiritual care therapy group than the control group

Spiritual care can enhance the self-efficacy of the family caregivers of people who suffer from Alzheimer's disease

The hope, life satisfaction, and spir- itual well-being of elderly patients with mild or moderate dementia could significantly be improved with a 6-week spiritual reminiscence intervention techniques such as knowing values and deep belief in God can decrease social stigma and worry in the mothers of the children with autism

Intervention: Spirituality

Therapy

Analyze: ANOVA

Effects of Spiritual Group Design: experimental study Therapy on Caregiver Strain Sample: 100 caregivers

In the intervention group in Home Caregivers of the Variables: Spiritual Group Elderly with Alzheimer's Therapy, Caregiver Strain in Disease (Mahdavi, Fallahi- Home

Khoshknab, Mohammadi, Intervention: Spiritual Group Hosseini, \& Haghi, 2017) Therapy

mean of the posttest care strain score $32.43 \pm 2.73$ was significantly lower than pretest 37.16 $\pm 1.26(\mathrm{P}<0.001)$. The mean posttest score of care strain was significantly Analyze: Chi-square, Fisher's lower in the intervention 


\section{STRADA Jurnal Ilmiah Kesehatan}

DOI: $10.30994 /$ sjik.v9i2.386

ISSN: 2252-3847 (print); 2614-350X (online)

Vol.9 No.2 November 2020 Page.790-800

\begin{tabular}{|c|c|c|}
\hline Research Title & Research methods & Results \\
\hline & $\begin{array}{l}\text { Exact test, one-way analysis } \\
\text { of variance and paired t-test }\end{array}$ & $\begin{array}{l}\text { group compared to the two } \\
\text { other groups }(\mathrm{P}<0.001) \text {. }\end{array}$ \\
\hline The Efective & Design: quasi-experimental & Spiritual therapy can be used \\
\hline on Spiritual & research & as an effective intervention to \\
\hline Self-Esteem & Sample: 24 participants & improve spiritual well-being, \\
\hline and Self-Efcacy & Variables: Spiritual Therapy, & self-esteem and self-effi- cacy \\
\hline on Hemodialysis (Darvishi, & Well-Being, & in patients on hemodialysis. \\
\hline \multirow[t]{4}{*}{ Otaghi, \& Mami, 2020) } & Self-Esteem and Self-Efcacy & This intervention is directed \\
\hline & Intervention: & to holistic care. It can be done \\
\hline & Therapy & interdisciplinary \\
\hline & Analyze: Kolmogorov test & $\begin{array}{l}\text { participation in caring and } \\
\text { psychological teams. }\end{array}$ \\
\hline
\end{tabular}

The Effect of Spiritual Care Design: quasi-experimental The implementation of on Mental Health in Mothers study

of Children With Cancer Sample: 25 mothers children with cancer can

(Nikseresht et al., 2016) Variables: Spiritual Care, improve their mental health.

Mental Health

Intervention: Spiritual Care

Analyze: Kolmogorov-

Smirnov test

The Impact of Spiritual Care Design: quai-experimental

Education on Anxiety in Sample: 80 caregivers

Family Caregivers of Variables: Spiritual Care

The result showed a difference between the level Patients with Heart Failure Education, Anxiety in Family the intervention $(\mathrm{P}=0.001)$. (Borji, Mousavimoghadam, Caregivers Anxiety level in the Salimi, Otaghi, \& Azizi, Intervention: Spiritual Care experimental group three 2019)

Education

Analyze: descriptive statistics and inferential statistics

Effect of Spiritual Care Design: experimental study Based on Ghalbe Salim on Sample: 40 participants Anxiety in Adolescent with Variables: Spiritual Care Cancer (Vazifeh doust, Based on Ghalbe Salim, Hojjati, \& Farhangi, 2019) Anxiety in Adolescent with Cancer I: Spiritual Care Education

Analyze: Mann-Whitney U test and t-test, weeks after intervention $(27.88 \pm 7.10)$ was significant in comparison with before intervention $(45.06 \pm 5.79)(\mathrm{P}$ $=0.001$ ).

There was no difference the score of anxiety before intervention in any of the dimensions of anxiety and the general dimension of anxiety in the case and control ( $\mathrm{P}<$ 0.01). However, the mean of anxiety score in the SC group before and after intervention was significantly $(75.25 \pm$ 15.2) (44.55 \pm 7.62), respectively. So that $50 \%$ of the post- test changes are due to the effect of the intervention

Spiritual Care Training for Design: quasi-experimental spiritual care training 


\section{STRADA Jurnal Ilmiah Kesehatan}

DOI: $10.30994 /$ sjik.v9i2.386

\begin{tabular}{cccc}
\hline Research Title & \multicolumn{2}{c}{ Research methods } & \multicolumn{2}{c}{ Results } \\
\hline Mothers of Children & with study & program & promotes
\end{tabular}

Cancer: Effects on Quality Sample: 42 mothers of spirituality, personalized care, of Care and Mental Health children with cancer religiosity and spiritual care of Caregivers (Borjalilu, Variables: Spiritual Care as well as decreasing anxiety Shahidi, Mazaheri, \& Training, Quality of Care and in mothers of children with Emami, 2016) Mental Health of Caregivers cancer and decreases anxiety. Intervention: Spiritual Care It may be concluded that Training Analyze: ANOVA spiritual care training could be used effectively in reducing distressful spiritual challenges in mothers of children with cancer.

The Effect of Emotion Design: RCT

Regulation Training on Sample: 32 participants Stress, Anxiety, and Variables: Emotion Depression in Family Regulation Training, Stress, Caregivers of Patients with Anxiety, and Depression in Schizophrenia:

A Family Caregivers of Patients Randomized Controlled with Schizophrenia Trial (Behrouian, Ramezani, Intervention:

Dehghan, Sabahi, \& Regulation Training Emotion methods has significantly Zarandi, 2020)

Emotion Regulation in Design: quasi-experimental Participants Diagnosed With Sample: 130 children and Attention Deficit adolescents Hyperactivity Disorder, Variables: Before and After an Emotion Regulation, Emotion Participants Regulation Intervention Diagnosed Attention Deficit (Sánchez, Lavigne, Romero, Hyperactivity Disorder \& Elósegui, 2019) Intervention: Emotion results suggest that despite Regulation Intervention ADHD children and Analyze: paired sample t-test. adolescents having social and emotional deficits secondary to the core symptom triad, emotional regulation in this group can be improved by the application of socioemotional intervention

Randomized Controlled Design: RCT

Trial of a Facilitated Online Sample: 170 participants

Positive Emotion Regulation Variables: Facilitated Online Intervention for Dementia Positive Emotion Regulation, Caregivers (Moskowitz et Dementia Caregivers al., 2019) Intervention: Emotion Regulation Intervention

This randomized controlled trial of the online facilitated positive emotion regulation intervention in dementia caregivers demonstrated small to medium effect sizes on caregiver well being and 


\section{STRADA Jurnal Ilmiah Kesehatan}

DOI: $10.30994 /$ sjik.v9i2.386

ISSN: 2252-3847 (print); 2614-350X (online)

Vol.9 No.2 November 2020 Page.790-800

\begin{tabular}{llll}
\hline Research Title & \multicolumn{2}{c}{ Research methods } & \multicolumn{2}{c}{ Results } \\
\hline & Analyze: & multilevel & shows promise for remotely \\
moderated & mediation delivered programs to \\
analyses & & improve psychological well- \\
& & being in caregivers of people \\
& with dementia and other \\
& chronic illnesses.
\end{tabular}

Effect of Emotion Regulation Design: RCT

Training Based on the Gross Sample: 60 parents

Model on Anxiety among Variables: Regulation

Parents of Children with Training Based on the Gross

Cancer (Bahrami, Sheikhi, Model, Anxiety

Baglooi, \& Mafi, 2020) Intervention:

Regulation

Training Based on the Gross

Model Analyze: analysis of variance (ANOVA) and independent $\mathrm{t}$-test.
The effect of emotion Design: RCT

regulation training on family Sample: 80 participants relationships of hyperactive Variables:

Emotion

children

Moghaddam,

\&Sahebalzamani, 2020)
(Arabi, regulation training, family relationships

Intervention: regulation training

Analyze: statistics and the analysis of covariance.
Keywords

Our findings demonstrated

that the mean age of participants was $32.5 \pm 5.09$ and $32.26 \pm 4.9$ years in the intervention and control groups, respectively. Total anxiety scores of the intervention and control groups pre-intervention were obtained as 33.9 \pm 7.1 and $34.3 \pm 7.4$, respectively. This score changed to $19.2 \pm 1.47$ in the test group and $33.73 \pm 1.36$ in the control group immediately postintervention. Moreover, three months post-intervention, the scores of $22.17 \pm 5.8$ and $34.03 \pm 6.96$ were observed in the control and intervention groups, respectively. The repeated measures ANOVA revealed a significant difference between the two groups in terms of the effect of the intervention $(\mathrm{P}<0.001)$. The emotion regulation training approach in mothers with hyperactive children improved both the motherchild relationship and the interactive spousal styles and can be considered by the managers of treatment and rehabilitation field as an adjunctive therapy for the families of these children. 


\section{STRADA Jurnal Ilmiah Kesehatan}

DOI: $10.30994 /$ sjik.v9i2.386

ISSN: 2252-3847 (print); 2614-350X (online)

Vol.9 No.2 November 2020 Page.790-800

\section{DISCUSSION}

In conducting this systematic review, fifteen research articles were evaluated to find out how spiritual care plays a role in reducing stress levels so that they can improve emotional regulation while caring for schizophrenic clients. Through this systematic review, we try to show that fifteen research articles have a positive role in spiritual care to increase positive emotions, there are five articles discussing emotion regulation.

A caregiver is defined as someone who lives with the patient and is directly involved in the patient's care for at least six months and does not experience mental disorders (Ali \& Bokharey, 2015) or for 1 year (Hegde, Chakrabarti, \& Grover, 2019). Most of the caregivers in several studies were women and were housewives (Salamizadeh, Mirzaei, and Ravari 2017). Caregiver relationships with clients who receive care can be very close, such as spouses, daughters, or sons-in-law (Ali \& Bokharey, 2015). Relationships make it easier for

Caregivers in schizophrenic clients can suffer psychological morbidity due to the burdens that are carried during the care and care of schizophrenic patients (Brillianita \& Munawir, 2014). Feelings of burden are often experienced by someone caring for family members diagnosed with mental illness so that they are often impatient and insincere in providing daily care for schizophrenic patients, as well as being stigmatized by others that can affect the entire family structure(Betül \& Küçük, 2015). Stigma from others and oneself is very detrimental to the continuity of caregiving from the schizophrenia client caregiver, this can hurt the emotional development of the schizophrenic client caregiver.

Emotional changes in the schizophrenic client caregiver are influenced by the psychological stress experienced by the caregiver in caring for schizophrenic clients (O'Toole et al., 2020). The caregiver's inability to regulate emotions causes negative emotions to emerge which can lead to negative consequences, including depression and anxiety while providing care and nurturing (Bahrami et al., 2020). Stress causes emotional dysregulation, which in turn will disrupt their psychological and physiological health (Compare et al., 2014). Emotional dysregulation experienced by caregivers will hurt their physical and psychological health, this will also affect the recovery process for schizophrenic clients. Therefore, a strategy is needed to improve the emotional regulation of the schizophrenic client caregiver while providing care for relatives who suffer from schizophrenia at home.

The spiritual role is very important to improve the psychological well-being of the caregiver for chronic disease clients so that it can prevent pathological influences such as hopelessness, depressed mood, anger, anxiety, and the burden of care (Anum \& Dasti, 2016). Besides, in a study conducted by Gruhn \& Compas, (2020), it was explained that spiritual care plays an important role in the recovery process for depression. Anxiety, stress, and anger can be well managed by involving spiritual care in everyday life including providing care for schizophrenic clients.

\section{CONCLUSION}

Spiritual care is carried out by providing spiritual-based education to the schizophrenic client caregiver by focusing on spiritual values such as maintaining a relationship with God while caring for schizophrenic clients, this will have a good impact on the recovery process for schizophrenic clients. 


\section{STRADA Jurnal Ilmiah Kesehatan}

DOI: $10.30994 /$ sjik.v9i2.386

ISSN: 2252-3847 (print); 2614-350X (online)

Vol.9 No.2 November 2020 Page.790-800

\section{REFERENCES}

Ali, S., \& Bokharey, I. Z. (2015). Efficacy of cognitive behavior therapy among caregivers of dementia: An outcome study. Pakistan Journal of Psychological Research, 30(2), 249-269. Retrieved from http://libproxy.nps.edu/login?url=https://search.proquest.com/docview/1915377169 ?accountid=12702\%0Ahttps://nps.primo.exlibrisgroup.com/discovery/openurl?insti tution=01NPS_INST\&vid=01NPS_INST:01NPS\&?url_ver=Z39.88-

2004\&rft_val_fmt=info:ofi/fmt:kev:mtx:jour

Altamura, C., Fagiolini, A., Galderisi, S., Rocca, P., \& Rossi, A. (2014). Schizophrenia today: Epidemiology, diagnosis, course and models of care. Journal of Psychopathology, 20(3), 223-243.

Anum, J., \& Dasti, R. (2016). Caregiver Burden, Spirituality, and Psychological WellBeing of Parents Having Children with Thalassemia. Journal of Religion and Health, 55(3), 941-955. https://doi.org/10.1007/s10943-015-0127-1

Arabi, Z., Moghaddam, L. F., \& Sahebalzamani, M. (2020). The effect of emotion regulation training on family relationships of hyperactive children. Journal of Education and Health Promotion, 9, 1-8. https://doi.org/10.4103/jehp.jehp_738_19 Department

Bahrami, S., Sheikhi, M. R., Baglooi, M. M., \& Mafi, M. (2020). Effect of emotion regulation training based on the gross model on anxiety among parents of children with cancer. Evidence Based Care Journal, 9(4), 40-47. https://doi.org/10.22038/ebcj.2020.42462.2138

Behrouian, M., Ramezani, T., Dehghan, M., Sabahi, A., \& Zarandi, B. E. (2020). The Effect of Emotion Regulation Training on Stress, Anxiety, and Depression in Family Caregivers of Patients With Schizophrenia: A Randomized Controlled Trial. Community Mental Health Journal. https://doi.org/https://doi.org/10.1007/s10597-020-00574-y

Betül, K., \& Küçük, L. (2015). Archives of Psychiatric Nursing Care Burden Level and Mental Health Condition of the Families of Individuals With Mental Disorders. https://doi.org/10.1016/j.apnu.2015.10.004

Borjalilu, S., Shahidi, S., Mazaheri, M. A., \& Emami, A. H. (2016). Spiritual care training for mothers of children with cancer: Effects on quality of care and mental health of caregivers. Asian Pacific Journal of Cancer Prevention, 17(2), 545-552. https://doi.org/10.7314/APJCP.2016.17.2.545

Borji, M., Mousavimoghadam, S. R., Salimi, E., Otaghi, M., \& Azizi, Y. (2019). The Impact of Spiritual Care Education on Anxiety in Family Caregivers of Patients with Heart Failure. Journal of Religion and Health, 58(6), 1961-1969. https://doi.org/10.1007/s10943-018-0689-9

Brillianita, K. A., \& Munawir, A. (2014). Hubungan antara Gejala Positif dan Negatif Skizofrenia dengan Tingkat Depresi pada Caregiver Pasien Skizofrenia. Jurnal Fakultas Kedokteran Universitas Jember, Vol. 3, 2-5.

Compare, A., Zarbo, C., Shonin, E., Van Gordon, W., \& Marconi, C. (2014). Emotional regulation and depression: A potential mediator between heart and mind. Cardiovascular Psychiatry and Neurology, 2014. https://doi.org/10.1155/2014/324374

Darvishi, A., Otaghi, M., \& Mami, S. (2020). The Effectiveness of Spiritual Therapy on Spiritual Well-Being, Self-Esteem and Self-Efficacy in Patients on Hemodialysis. 


\section{STRADA Jurnal Ilmiah Kesehatan}

DOI: $10.30994 /$ sjik.v9i2.386

ISSN: 2252-3847 (print); 2614-350X (online)

Vol.9 No.2 November 2020 Page.790-800

Journal of Religion and Health, 59(1), 277-288. https://doi.org/10.1007/s10943018-00750-1

Gruhn, M. A., \& Compas, B. E. (2020). Effects of maltreatment on coping and emotion regulation in childhood and adolescence: A meta-analytic review. Child Abuse and Neglect, 103(March). https://doi.org/10.1016/j.chiabu.2020.104446

Hegde, A., Chakrabarti, S., \& Grover, S. (2019). Caregiver distress in schizophrenia and mood disorders: the role of illness-related stressors and caregiver-related factors. Nordic Journal of Psychiatry, 73(1), 64-72. https://doi.org/10.1080/08039488.2018.1561945

Mahdavi, B., Fallahi-Khoshknab, M., Mohammadi, F., Hosseini, M. A., \& Haghi, M. (2017). Effects of Spiritual Group Therapy on Caregiver Strain in Home Caregivers of the Elderly with Alzheimer's Disease. Archives of Psychiatric Nursing, 31(3), 269-273. https://doi.org/10.1016/j.apnu.2016.12.003

Marlindawani Purba, J., \& Karota Bukit, E. (2017). The Effect of a Psychoeducation Intervention on Burden Among Caregivers of Persons with Schizophrenia in Medan. (November). https://doi.org/10.2991/phico-16.2017.69

Moskowitz, J., Cheung, E., Snowberg, K., Verstaen, A., Merrilees, J., Salsman, J., \& Dowling, G. A. (2019). Emotion Regulation Intervention for Dementia Caregivers. Health Psychology, 38(5), 391-402. https://doi.org/10.1037/hea0000680.Randomized

Mousavi Najafi, F., \& Rasouli Jozi, F. (2019). Effectiveness of Spirituality Therapy on Social Stigma and Worry in the Mothers of the Children with Autism. Social Behavior Research \& Health, 3(2), 410-418. https://doi.org/10.18502/sbrh.v3i2.1787

Nikseresht, F., Rassouli, M., Torabi, F., Farzinfard, F., Mansouri, S., \& Ilkhani, M. (2016). The effect of spiritual care on mental health in mothers of children with cancer. Holistic Nursing Practice, 30(6), 330-337. https://doi.org/10.1097/HNP.0000000000000175

O’Toole, M. S., Mennin, D. S., Applebaum, A., Weber, B., Rose, H., Fresco, D. M., \& Zachariae, R. (2020). A randomized controlled trial of emotion regulation therapy for psychologically distressed caregivers of cancer patients. JNCI Cancer Spectrum, 4(1), 1-9. https://doi.org/10.1093/jncics/pkz074

Salamizadeh, A., Mirzaei, T., \& Ravari, A. (2017). The impact of spiritual care education on the self-efficacy of the family caregivers of elderly people with Alzheimer's disease. International Journal of Community Based Nursing and Midwifery, 5(3), 231-238.

Sánchez, M., Lavigne, R., Romero, J. F., \& Elósegui, E. (2019). Emotion regulation in participants diagnosed with Attention Deficit Hyperactivity Disorder, before and after an emotion regulation intervention. Frontiers in Psychology, 10(MAY), 1-10. https://doi.org/10.3389/fpsyg.2019.01092

Sankhe, A., Dalal, K., Save, D., \& Sarve, P. (2017). Evaluation of the effect of Spiritual care on patients with generalized anxiety and depression: a randomized controlled study. Psychology, Health and Medicine, 22(10), 1186-1191. https://doi.org/10.1080/13548506.2017.1290260

Vazifeh doust, M., Hojjati, H., \& Farhangi, H. (2019). Effect of Spiritual Care Based on Ghalbe Salim on Anxiety in Adolescent with Cancer. Journal of Religion and Health, (0123456789). https://doi.org/10.1007/s10943-019-00869-9 


\section{STRADA Jurnal Ilmiah Kesehatan}

DOI: $10.30994 /$ sjik.v9i2.386

ISSN: 2252-3847 (print); 2614-350X (online)

Vol.9 No.2 November 2020 Page.790-800

Von Kardorff, E., Soltaninejad, A., Kamali, M., \& Shahrbabaki, M. E. (2016). Family caregiver burden in mental illnesses: The case of affective disorders and schizophrenia - A qualitative exploratory study. Nordic Journal of Psychiatry, 70(4), 248-254. https://doi.org/10.3109/08039488.2015.1084372

Wu, L. F., \& Koo, M. (2016). Randomized controlled trial of a six-week spiritual reminiscence intervention on hope, life satisfaction, and spiritual well-being in elderly with mild and moderate dementia. International Journal of Geriatric Psychiatry, 31(2), 120-127. https://doi.org/10.1002/gps.4300 